ISSN: 2637-773X

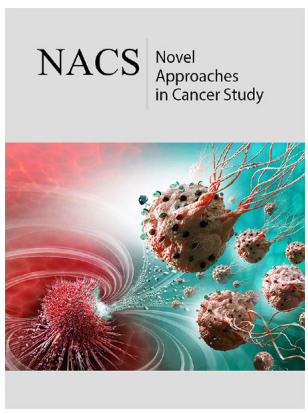

*Corresponding author: : Irfan M Lone, Master's In psychology, Hollandstraat 24, Antwerpen 2060 Belgium

Submission: 㻗: October 13, 2020

Published: 眥 December 08, 2020

Volume 5 - Issue 4

How to cite this article: Irfan $M$ Lone. Impact of Cancer Diagnosis on Emotional Well Being and Quality of Life on Lgbt Population in India and Across Europe; A Report Drawn on the Bases on Experience and Birds Eye View of a Psycho-Oncologist. Nov Appro in Can Study. 5(4). NACS.000618. 2020. DOI: 10.31031/NACS.2020.05.000618

Copyright@Irfan M Lone, This article is distributed under the terms of the Creative Commons Attribution 4.0 International License, which permits unrestricted use and redistribution provided that the original author and source are credited.

\section{Impact of Cancer Diagnosis on Emotional Well Being and Quality of Life on Lgbt Population in India and Across Europe; A Report Drawn on the Bases on Experience and Birds Eye View of a Psycho-Oncologist}

\author{
Irfan M Lone* \\ Master's In psychology, Belgium
}

\section{Opinion}

In order to draw significant comparisons between the disparities in dealing with LGBT cancer patients in East and West, it becomes extremely essential for us, as clinicians and health care providers to understand the bigger picture of the LGBT Community in general. As we all know that in India we still have not been able to reach a point where all the people are accepted unconditionally; and when it comes to sexual orientation, we still face old taboos, socio-cultural and religious pressures, prejudice, and judgments in general. Moreover, while dealing with clients belonging to the LGBT community, clinicians also doesn't have it easy. In India, we still do not approve same-sex marriages and the rights of the LGBT community are still not fully recognized, which puts this group on the lines of extreme vulnerability, both emotional and otherwise. On the other hand, the acceptance from family and friends, the government, and the general public and endless fear of ending up alone all life, makes things worse. However, thankfully the younger generation in India seems to be more accepting, possibly due to the social media explosion from last decade, or possibly due to easy access to worldwide web, mobile phones, and so on, and therefore, cultural and ideological exchanges with "online friends" abroad and also to some extent due to changing norms in Indian cinema.

On the other hand, however, in the west, specifically in Europe most of the countries give full rights and acknowledgments to all the individuals belonging to the LGBT group; they can get married, have children or adopt children and possess properties, dress the way they want to, be open and free and take pride in their sexual orientations, have equal opportunity in the job market and thus have normal married and committed life and so on, but this doesn't mean that they don't face challenges here. This community faces unique challenges here as well, sometimes more serious than anywhere else, but in the long run, these challenges are mostly practical and in most of the cases tangible and thus resolvable; besides the support from the government and political system and therefore society as a whole makes the situations and scenarios different here.

Both in India or west, any gay, lesbian, or anyone belonging to the LGBT community, after hearing "The Bad News of BIG C" experience the same emotions and shock waves, however as far as my experience in India goes, Indian patients feel these emotions to more extreme levels and their implications are highly significant. Fear of getting the sexual orientation disclosed after the diagnosis, fear of being judged by clinicians, and in extreme cases fear of being disowned by family and caregivers are the primary apprehensions or stressors that can profoundly impact the mental well-being and thus the quality of life of such patients. In some case, I have also seen that these fears significantly impact the decision-making process 
about treatment and therapies, (in such cases, the patients let treating oncologists decide for them, "because if it helps to protect my sexual orientation, it works for me, moreover doctors are the experts to decide for my treatment").

My experience in the field of psycho-oncology in India and also the great opportunity to work in South -East Asia's biggest cancer hospital, I have had multiple clients, who were not out to their families, but due to cancer diagnosis, there were situations when they had to break the secret of their sexual orientation, which was most of the times very difficult for me as a clinician to deal with; given the fact that my role was highly essential in treatment process, I should make sure that family is in peace with this truth and accepts the patient as he/she is. The other side of the coin of Clinical/professional difficulty was that this truth should only be reviled to psycho-oncologist/ psychologist (in this case me), other than the family (Mostly father and mother). In most of the cases, even siblings should not know about this. Sexual orientation should not be disclosed in any way with the rest of the treating team, absolutely no body. The therapies with patient and family would sometimes last for months, irrespective of socio-economic status, or education of the family. Now for the family, there were two types of catastrophes to deal with, the BIG ' $\mathrm{C}$ ' and the Orientation of their child. But in most of the cases both the parties would come to a peaceful acceptance. Because "saving lives and treating Cancer is Most essential and therefore priority at that moment. "Sexual orientation can be dealt with later, "Because I know few of the Baba Jis, they can surely help us". These are the words of a father of 24-year-old Rectum cancer Namit, who said he needs to disclose the orientation before he gets started with cancer treatment. Namit was studying for aviation and was an aspiring Pilot, had a long term 4-year stable relationship with a guy called (Amar). Both the families didn't know about the sexual orientations of their sons, yet Namit came out to his family after 3 weeks of knowing his cancer diagnosis. Unfortunately, Namit passed away after 15 months of his diagnosis, the disease was already in metastasis and it didn't respond to any sort of therapy. The last months and weeks were hard for Namit and the family. (the names of the persons have been changed for professional confidentiality)

On the other hand, however, in Belgium for example, LGBT people are very open, as I discussed before, have an equal position and opportunities in society. The issues and stressors are completely different and unique than in India, however, the basic issues are the same for any cancer patient, when he/she gets to know about the cancer diagnosis, but here the fundamental basic issues revolve round work, relationship, and logistics, which are more tangible or practical, if we look at them in-depth and with a logical eye, which doesn't in any way mean that the shock and disbelief is not experienced here by this group. The primary emotional issues in Belgium according to my experience however are.

1. If the relationship or commitment or partnership will continue after cancer diagnosis.
2. Identifying and accepting the role changes in relationship (from a partner, lover or husband and so on to care-giver)

3. Managing Logistics, for example with work and family life.

4. Body image issues among younger patients (the younger the patient, the stronger the intensity)

5. Negative implications on dating and sexual behaviors after diagnosis

\section{Disparities in self-image}

However, after the treatment gets started, gradually the information and knowledge of cancer diagnosis, treatment, and prognosis (prognosis, mostly in European patients, because in the east, specifically in India patients are not yet told about clear prognosis, but it has improved over the past decade) sink in and these issues come to peace, which I have experienced and observed with Indian counterparts, lasts even longer and in most of the case go along the whole trajectory of the cancer journey and sometimes even after treatment.

To a great extent, the solutions to these fundamental issues are directly correlated to the quality of caregiving and social support. The diagnosis of cancer also brings a great deal of challenges in the family stricture, dynamics, and "Normalcy." Given the fact that caregiving can be a delightful gift one can offer to change the picture of the cancer journey; on the other hand, it can be extremely irritating and can profoundly impact the quality of life of the caregiver. Burnout, verbal assault, irregularities in professional and social life, mood disorders, chronic and acute stress, and fatigue are the basic issues reported globally by caregivers, irrespective of cultural or religious backgrounds. In India, the primary caregivers are family (Parents) and is seen more structured and organized when it comes to caring for LGBT patient, but in Europe (Belgium) the primary caregiving is offered by partner or lover or husband/ wife (if the patient is committed, legal partnership or married) family and friends follow the line. But if the patient is single due to any reason, primary caregiving is provided by family (including parents and siblings), followed by friends. In Belgium, both heterosexual and the LGBT cancer patients enjoy their social lives, even during the treatment of cancer, and thus going out, meeting friends and family, organizing small feasts, and so on doesn't make them feel that they need care all the time, which on the other hand in India, patients are mostly forbidden to go out in gatherings and thus are confined to home or in hospital, which makes them feel and believe that they are sick, thus need care all the time. This, in turn, puts the caregivers in India generally on a spectrum of unique challenges ranging from mood disorders, fatigue to clinical depression.

Psychologists and Psycho-oncologists need to be extremally empathetic and possess a non-judgmental attitude, especially in India. Clients belonging to this community must feel safe and secure, to first bring the issues about sexual orientation on the table and secondly, to feel a sense of deep trust and respect with 
a psychologist to resolve challenges concerning orientation alongside the cancer therapies. Such cases should not be considered as "glittering and rainbow disco lights decorating the ceilings" (by this, I mean a psychologist should never highlight in their professional profile, with laughter, pride and fun, that these cases were or are being dealt by him/her). But this doesn't mean that such cases should be regarded as special ones, rather they should be considered highly sensitive and extremely confidential.

Indeed, Special education focusing on LGBT and cancer could certainly uplift the sensitivity of such cases, make clinicians more aware of this group of patients, and likewise make them more confident and practical in dealing with such patients. Other clinical professionals including, nurses and oncologists along with primary caregivers, families, and close ones could also be sensitized over this subject, which in turn will ultimately reflect that "we do not discriminate them in health care and we do our best to take care of them as One Clinical Team".

Some of the common issues reported by LGBT survivors after the completion of cancer treatment in no particular order in Belgium are:

Long-term psychological Distress with or without comorbid another DSM diagnosis
a) Depression and loneliness
b) High intensity of Body Image Issues
c) Uncertainty in existing relationships or starting a new serious committed relationship.

d) Intense feelings of physical and sexual undesirability

e) Apprehension to openly participate in dating behaviors

f) Inconsistency with job profiles.

(The above-mentioned issues go in line with Indian context, which gives me an impression that these issues are at the core in every society when we focus on LGBT and cancer as a whole)

There is a lot to offer in terms of breaking the stigma about LGBT and cancer, however, I feel it falls in the broader and huge domain of Sexual Orientation and socio-cultural and religious norms and belief systems in India or any society in general. Yet on the other hand, as Clinicians and oncology professionals we form a big group together and if we, as a big group open our hearts and hands to serve and care for them with compassion, that would be already a great start and the legacy would be build up in our professionalism, and possibly other professionals will be inspired and they will also follow the steps and ultimately, we will create a society where everyone is loved, respected and given ultimate care they deserve, irrespective of caste, color, religion or orientation.

Besides, we need to start exploring the area of LGBT and cancer, to formulate some special guidelines for handling and care for this super special, yet highly vulnerable group.

"If cancer never discriminates people, why should we as clinicians do so; let's pledge to defeat cancer with love and compassion." 